\title{
Risk Prediction of Sinkhole Occurrence for Different Subsurface Soil Profiles due to Leakage from Underground Sewer and Water Pipelines
}

\author{
Haibat Ali $[$ and Jae-ho Choi * (ID \\ Civil Engineering, Dong-A University, Busan, P4401-1, 550 Bungil 37, Nakdong-Dero, Saha-Gu 49315, Korea; \\ 1772901@donga.ac.kr \\ * Correspondence: jaehochoi@dau.ac.kr; Tel.: +82-51-200-762
}

Received: 2 December 2019; Accepted: 26 December 2019; Published: 31 December 2019

\begin{abstract}
A sinkhole is a ground surface depression that may occur with or without any indications on the surface and often pose danger to both properties and people. Leakage from underground pipe mains in urban areas may cause sudden ground subsidence or sinkholes. For a long time, researchers have been working on the hazard and risk assessment of sinkhole formation, especially natural sinkholes. However, much less work has been done on risk prediction and the mechanism of manmade sinkholes. In this study, different versions of small-scale sinkhole physical models were used in experiments to monitor ground surface settlement or collapse due to leakage from an underground pipeline. The factors under consideration were the type of subsurface soil profile, type of water flow, and leakage position in the pipeline. The ultimate goal was to use this information to predict the risk of sinkhole occurrence due to leakage from sewer or water pipelines under different subsurface soil conditions. The experimental results and statistical analysis showed that the subsurface soil strata conditions dominated the mechanism of sinkhole occurrence, although other factors also have contributed to the settlement. Then, this analysis was used to predict the sinkhole risk level under different conditions. The development of a reliable sinkhole risk prediction system can potentially minimize the risk to human lives and infrastructure. These findings can be applied to the development of a sinkhole risk index (SRI) that considers various other factors influencing sinkhole occurrence.
\end{abstract}

Keywords: sinkhole; risk prediction; sewer pipeline; pipeline leakage; soil profile

\section{Introduction}

Urbanization is accompanied by the rapid development of both the surface and subsurface of urban areas and impacts the environment in various ways. Rapid urbanization and expanding land usage have increased damage to subsurface infrastructures such as sewer and water pipelines, which results in pipeline leakage. The increasing leakage from sewer and water pipelines and ground collapse in urban areas due to excavation, pipe aging, underground construction [1], and tree root growth has resulted in damaging the underground infrastructures and water pipelines and hence causing leakage, which results in ground subsidence and sinkholes. The different types of tunneling methods that have been adopted for the construction of various underground subways in urban areas have a huge impact on the nearby utilities such as sewer and water pipelines [2]. A sinkhole is a cavity in the ground that is formed by underground erosion and depression of the ground surface. There are two types of sinkholes: natural and manmade. Manmade sinkholes are associated with leakage from sewer and water pipelines and soil erosion. 
Manmade sinkholes due to water leakage from underground sewer and/or water pipelines have become a critical concern of water management authorities in both developed and developing countries around the world. According to Kang et al. (2017) [3], most manmade sinkholes or ground subsidence result from leaking underground sewer pipelines. Due to rapidly increasing cases and reports in metropolises and cities, sinkholes have become recognized as a primary hazard that can cause massive infrastructure and financial losses to society [4]. Sinkholes can occur very suddenly and lead to extensive damage, especially in urban areas. From 2006 to 2010, the Florida Office of Insurance Regulation in the USA registered over 24,671 cases of sinkholes that caused financial damage of around 1.4 billion USD [5]. Factors such as groundwater extraction, construction in adjoining areas, and leakage from underground pipelines are the driving causes of sinkholes in urban areas [6]. The size of a sinkhole can range from $2 \mathrm{~m}$ deep and $1.5 \mathrm{~m}$ wide [7] to enormous scales of up to $15 \mathrm{~m}$ deep and 30 $\mathrm{m}$ wide [8], as reported in Jeju, South Korea, and southwest Japan. In the USA, manmade sinkholes have been reported in San Antonio, Texas, [9], Oakwood, Georgia, and Tracer, Colorado [10]. These incident have caused immense economic damage while also claiming human lives.

Some of the most complex civil engineering problems stemming from the interaction between water and soil are sinkholes and ground subsidence. Sinkholes induced by leaking underground pipelines have become a significant challenge that needs to be intensively studied. Previous research has concentrated on natural sinkholes and primarily observed regions with large deposits of salt, limestone, and carbonate rocks. Accurately predicting the sinkhole location and time of occurrence is rather difficult [11]. As urban areas grow, they increasingly require buried pipeline systems to supply water and provide drainage. These issues further exacerbate the infrastructure and environmental conditions that underpin human socioeconomic activities. Applying a monitoring method (e.g., conventional or wireless sensor networks) along the pipeline network of a metropolitan city can be costly, energy-intensive, time-consuming, and complicated. Hence, it is essential to predict the areas with a high risk of sinkholes and ground subsidence first and to monitor these high-risk areas to save time, energy, and money.

Natural and manmade sinkholes cannot be directly detected. The development of a sinkhole risk index (SRI) or sinkhole risk prediction should help correlate the leakage from pipelines with sinkhole detection. Researchers have considered developing an SRI to determine risk elements for sinkhole occurrence and ground subsidence [12]. For a long time, researchers have been working on hazard and risk assessment of sinkhole formation, especially natural sinkholes. Table 1 presents the research contributions to sinkhole risk assessment for natural and manmade sinkholes and their limitations. According to Table 1, four out of eight contributions are related to manmade sinkholes. Only four research contributions [12-15] focused on predicting the risk of manmade sinkhole formation. Two contributions $[12,13]$ concentrated only on manmade sinkholes due to leakage from underground sewer and water pipelines. In most previous research, authors only focused on karstic soil profiles (i.e., soil profiles with carbonate rock and limestone). This indicates that less work has been done on the risk prediction of manmade sinkholes (due to leakage in underground water pipelines), as presented in Table 1.

Among those two contributions [12,13], the authors in [12] only considered the deflection of water pipelines after leakage as a factor for sinkhole risk prediction. Other than that, this study [12] is just limited to soil profiles with karstic soil profiles. Kwak et al. (2015) [13] contributed toward the risk assessment of sinkholes due to leakage from underground sewer or water pipelines; however, their risk assessment model is still under development. 
Table 1. Overview of previous research contributions to sinkhole risk assessment for natural and manmade sinkholes.

\begin{tabular}{|c|c|c|c|c|}
\hline \multirow{2}{*}{ Ref. } & \multicolumn{2}{|c|}{ Sinkhole Type } & \multirow{2}{*}{ Objective } & \multirow{2}{*}{ Limitations } \\
\hline & N-S & M-S & & \\
\hline [16] & $\bullet$ & & $\begin{array}{l}\text { Hazard and risk assessment for } \\
\text { sinkholes }\end{array}$ & $\begin{array}{l}\text { Only assessed sinkholes on dolomite } \\
\text { land }\end{array}$ \\
\hline [17] & $\bullet$ & & $\begin{array}{l}\text { Numerical modeling and finite- } \\
\text { element analysis of undrained } \\
\text { stability for submerged cavities that } \\
\text { may form sinkholes }\end{array}$ & $\begin{array}{l}\text { Focused only on natural sinkholes } \\
\text { that occur in the presence of limestone }\end{array}$ \\
\hline [15] & $\bullet$ & $\bullet$ & Sinkhole risk assessment & $\begin{array}{l}\text { Focused only on infrastructure over } \\
\text { karstic ground }\end{array}$ \\
\hline [12] & & $\bullet$ & $\begin{array}{l}\text { Application of Internet of Things to } \\
\text { monitoring sinkholes due to leakage } \\
\text { from sewer and water pipelines }\end{array}$ & $\begin{array}{l}\text { Sinkhole risk index for manmade } \\
\text { sinkhole is still under development }\end{array}$ \\
\hline [6] & $\bullet$ & & $\begin{array}{l}\text { First trial to detect sinkholes with a } \\
\text { thermal camera attached to a drone }\end{array}$ & $\begin{array}{l}\text { Monitoring only natural sinkholes } \\
\text { Lost or false detection of sinkholes } \\
\text { due to fast movement of the drone }\end{array}$ \\
\hline [11] & $\bullet$ & & $\begin{array}{l}\text { Prediction of sinkhole susceptibility } \\
\text { hazard zones using GIS and the } \\
\text { analytical hierarchical process (AHP) }\end{array}$ & $\begin{array}{l}\text { Needs to use suitable techniques } \\
\quad \text { other than AHP } \\
\text { High-resolution satellite images } \\
\text { needed for reliable results }\end{array}$ \\
\hline [14] & & $\bullet$ & $\begin{array}{l}\text { Prediction of ground subsidence risk } \\
\text { due to excavation activities }\end{array}$ & $\begin{array}{l}\text { Not applicable to cases other than } \\
\text { excavation }\end{array}$ \\
\hline [13] & $\bullet$ & $\bullet$ & $\begin{array}{l}\text { Detection of sinkhole development } \\
\text { using pipe deflection }\end{array}$ & $\begin{array}{l}\text { Limited to areas with a karstic soil } \\
\text { profile } \\
\text { Deflection is the only factor } \\
\text { considered }\end{array}$ \\
\hline
\end{tabular}

Ali and Choi (2019) [18] showed that many methods such as the application of aquatic sensors, vibration sensors, GIS, robotic devices, thermal images, and conventional methods are available for sewer pipeline inspection. However, little research has focused on addressing sinkholes due to leakage from underground pipelines. Thus, more research is needed on the risk assessment and prediction of manmade sinkholes, more specifically manmade sinkholes, due to leakage in underground water pipelines [18]. The above literature review showed that one of the main factors accelerating sinkhole or ground subsidence is the soil strata beneath the leakage point [15]. Other factors includes the type of flow of water inside the pipeline and the location of the leakage. These factors can potentially be used as indicators for the risk level of a sinkhole due to leakage [12]. The subsurface soil profile varies with the area and is characterized by its unique geomorphology and hydrology [16]. The effect of water leaking from a sewer or water pipeline on surrounding soil differs according to the subsurface soil profile.

The objectives and outcomes of previous relevant sinkhole models and experimental studies are presented in Table 2. These models have been mainly developed for naturally occurring sinkholes. In addition, each research group focused on one type of soil profile, and no study considered the effect of the type of water flow or the leakage position on the sinkhole occurrence. On the basis of the literature review, the authors in this study came to know that no research considered manmade sinkhole, and subsurface soil profile, type of water flow, and leakage position in the pipeline as the factors affecting the sinkhole due to leakage in underground pipelines. Hence, in this study, the authors considered all these factors to study and understand the mechanism of manmade sinkhole because of leakage in underground pipelines in different types of subsurface soil profiles. 
Table 2. Different aspects and characteristics of previous experimental, numerical, and mechanical sinkhole models.

\begin{tabular}{|c|c|c|c|c|c|}
\hline Ref. & $\begin{array}{c}\text { Type of } \\
\text { Sinkhole }\end{array}$ & $\begin{array}{c}\text { Factors } \\
\text { Considered }\end{array}$ & Type of Soil & Objective & Remarks \\
\hline [19] & Natural & $\begin{array}{l}\text { Groundwater } \\
\text { level and size } \\
\text { of cavity }\end{array}$ & Sand and clay & $\begin{array}{l}\text { Understanding the mechanism of } \\
\text { natural sinkholes due to } \\
\text { groundwater changes through } \\
\text { numerical simulation }\end{array}$ & $\begin{array}{l}\text { Needs more improvement of } \\
\text { simulation method to increase } \\
\text { simulation capabilities }\end{array}$ \\
\hline [20] & Natural & $\begin{array}{l}\text { Size of cavity, } \\
\text { overburden } \\
\text { thickness, and } \\
\text { groundwater } \\
\text { table }\end{array}$ & $\begin{array}{l}\text { Clayey soil and } \\
\text { limestone rock }\end{array}$ & $\begin{array}{l}\text { Numerical simulation to } \\
\text { understand geometrical behavior } \\
\text { around sinkholes along the Dead } \\
\text { Sea }\end{array}$ & $\begin{array}{l}\text { Key characteristics of sinkhole } \\
\text { subsidence and feasibility of } \\
\text { geotechnical approach derived to } \\
\text { improve understanding of natural } \\
\text { sinkhole development along the } \\
\text { Dead Sea } \\
\text { Only sinkholes and soil types of } \\
\text { seaside areas were considered }\end{array}$ \\
\hline [21] & Natural & $\begin{array}{l}\text { Salt dissolution } \\
\text { Groundwater } \\
\text { table }\end{array}$ & Sea clay & $\begin{array}{l}\text { Understanding the mechanism of } \\
\text { sinkhole occurrence at the seaside }\end{array}$ & $\begin{array}{c}\text { Water level is the crucial factor for } \\
\text { the dissolution of salt and hence } \\
\text { sinkhole occurrence }\end{array}$ \\
\hline [23] & Natural & $\begin{array}{l}\text { Confined and } \\
\text { unconfined } \\
\text { aquifer }\end{array}$ & Sand & $\begin{array}{c}\text { Physical and numerical } \\
\text { investigation on the behavior of } \\
\text { natural sinkholes in central } \\
\text { Florida }\end{array}$ & $\begin{array}{l}\text { Only sand and natural sinkholes } \\
\text { in central Florida were considered }\end{array}$ \\
\hline
\end{tabular}

The aim of this study was to evaluate and predict the risk level of sinkhole occurrence under different subsurface soil conditions after leakage from underground water pipelines. The behavior (failure) of soil surrounding the leaking pipeline was dependent on the type of soil profile and the type of flow inside the pipeline. Various soil profiles were used in laboratory experiments to simulate diverse geological subsurface conditions such as soil profile with a cavity or a soil profile having lime stone or carbonate rocks. Thirteen scaled physical models were developed for experiments to understand the effects, risk, and mechanism of sinkhole occurrence due to leakage from underground water pipelines. The risk level in each scenario was predicted on the basis of settlement in each case, and a soil profile having lime stone and carbonate rocks with a non-continuous flow in pipeline was found to the most risky. A system was designed to measure the settlement rate over time under various conditions for the subsurface soil, water flow, and leakage position. The results should help with predicting potential high-risk zones in urban areas based on dynamic changes in critical factors such as the type of subsurface soil, type of water flow inside a pipeline, and leakage location on pipeline.

\section{Experimental Method}

The first stage of the experiment was to design the architecture in the laboratory. The overall architecture of the experimental setup is shown in Figure 1a. Water was supplied to the system from a water tank (Tank 2) with a capacity of 227 liters. The water passing through the pipeline was collected at the other end (outlet). The collected water at the outlet lets the authors know about the quantity of water, which is seeped into the model box through the leakage. In total, 200 liters of water were inside the water tank for each case. The pressure of the water flow declines steadily with the water level inside the water tank (inlet), so another water tank (Tank 1) was used to maintain the water level in Tank 2 to control the drop in water pressure, as shown in Figure 1a. A solenoid valve was fixed at the bottom of each water tank to manually control the flow of water inside the pipeline. A PVC (Polyvinyl Chloride) pipeline with an external diameter of $40 \mathrm{~mm}$ and internal diameter of $36 \mathrm{~mm}$ was used. Artificial leakage was created by making a hole in the pipeline, as shown in Figure 1c. The model box used for the experiment had dimensions of $700 \mathrm{~mm}$ (width) $\times 600 \mathrm{~mm}$ (length) $\times 330 \mathrm{~mm}$ (height) with a hole at the center of the bottom for drainage. The different subsurface soil profiles considered in this study comprised bedrock, carbonate rock, cavities, sand, and clay. 
Four soil profiles were considered: sandy clay (SC), sandy clay-bedrock (SC-BR), sandy clay-cavity-bedrock (SC-C-BR), and sandy clay-limestone-bedrock (SC-LS-BR). In addition, two water flows in the pipeline were considered: continuous and cyclic. The materials adopted for the 13 different soil profile models in the laboratory included sandy clay, limestone, sugar cubes, and gravel. Coarse aggregate (gravel) was used to represent bedrock, limestone powder was used to represent limestone, and sugar cubes were used to represent artificial cavities as shown in Figure $1 \mathrm{~b}$. In Figure $1 \mathrm{a}, \mathrm{b}$, the four different soil profiles under consideration in this study are represented as A, B, C, and D. In each of the 13 cases, the soil was compacted in two layers that were each $160 \mathrm{~mm}$ in thickness. The soil was compacted manually with a brick having dimensions of $20 \mathrm{~cm} \times 6.3 \mathrm{~cm} \times 5 \mathrm{~cm}$, and 20 vertical blows were used for each case. To measure the settlement in each case, a meter tape was attached vertically to the center of each model box, and the reading was recorded in millimeters (see Figure 1a). A camera was used to capture images of the experiment at the beginning and end of each case.

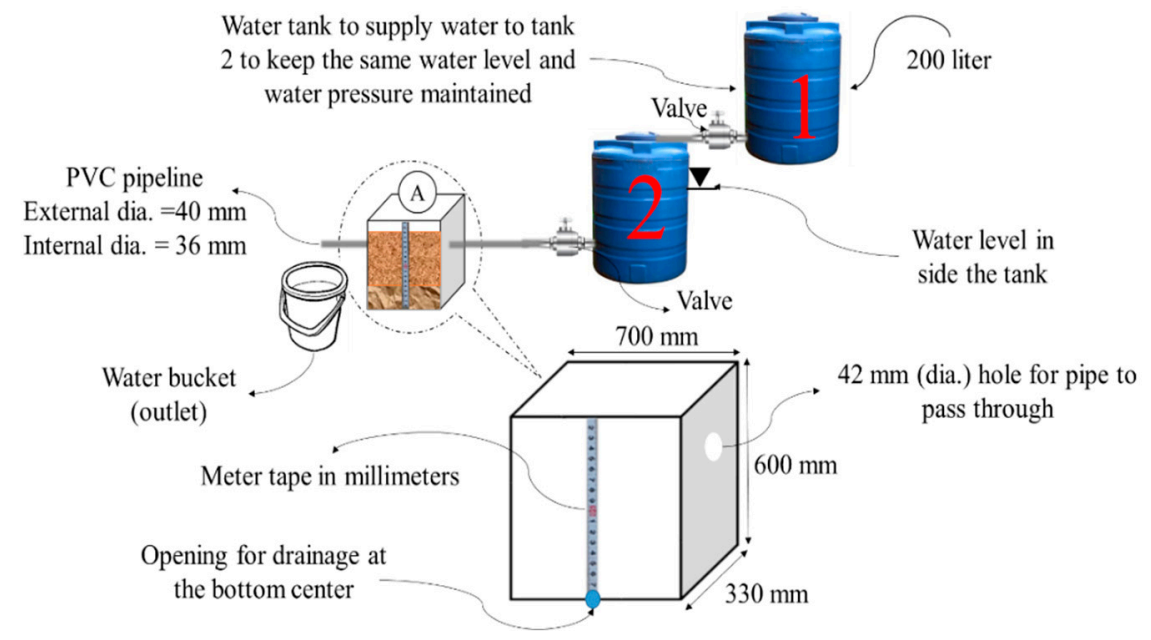

(a)

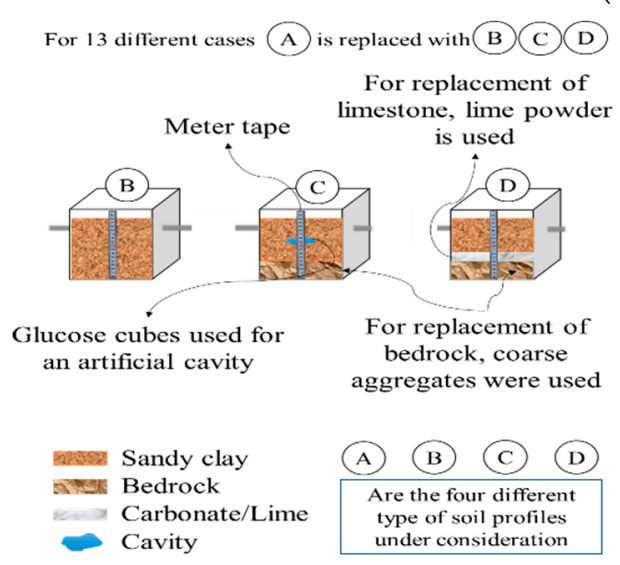

(b)

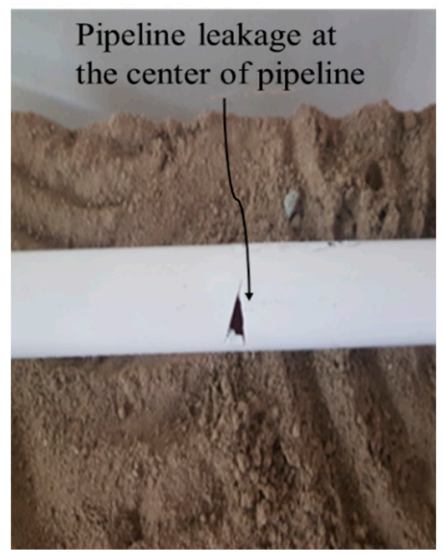

(c)

Figure 1. (a) Overall experimental setup and dimensions and details of each material used. (b) Different kinds of subsurface soil profiles considered for the experiment. (c) Leakage (hole) from the pipeline. Table 3.

The physical and mechanical properties of sandy clay used in this experiment are presented in 
Table 3. Physical and mechanical properties of sandy clay used in the experiments [24].

\begin{tabular}{cc}
\hline Properties & Value \\
\hline Liquid limit $=\mathrm{w}_{1}$ & 37.4 \\
Plasticity limit $=\mathrm{w}_{\mathrm{p}}(\%)$ & 12.3 \\
Void ratio $=\mathrm{e}_{\mathrm{o}}$ & 0.41 \\
Natural moisture $=\mathrm{w}_{\mathrm{n}}(\%)$ & 12.82 \\
\hline
\end{tabular}

The 13 subsurface soil profiles considered in this laboratory experiment were organized into three different cases based on the type of water flow and location of leakage in the pipeline. Case I comprised four different subsurface soil profiles. The flow inside the pipeline was continuous, and the leakage in the pipeline was from the bottom side of the pipeline, which was in contact with the flowing water. Case II used the same soil profiles and leakage position as Case I, but the flow of water inside the pipeline was cyclic. In this case, each of the four soil profiles was tested separately for two different cyclic flows: a time interval of $5 \mathrm{~s}$ and a time interval of $30 \mathrm{~s}$. In both scenarios, the cyclic flow was controlled by manually closing and opening the valve for the given time interval. In Case III, the flow of water was continuous, and the leakage was at the top of the pipeline, which was not in contact with the water flow. In this case, only one soil profile was considered, because only the soil above the pipeline would influence the occurrence of a sinkhole when the pipeline is leaking from the top. All three cases described previously are illustrated in Figure 2.

In this study, the two types of flow of water inside a water pipeline were adopted by considering the real scenarios. As in real scenarios, the water pipelines may have continuous or cyclic flow inside a pipeline; either it is water or sewer pipeline. Karoui et al. (2018) [25] also showed that the ground subsidence is more rapid for cyclic flow compared to continuous flow. The authors in [25] performed physical modeling of a sewer pipe defect in a silica sand model box in a laboratory to understand the sinkhole mechanism and the effect of water. Similarly, when real scenarios are considered, the leakage position in a water pipeline can be either at the top (the surface of pipeline that is not in contact with water) or at the bottom (the surface of the pipeline that is in contact with water) of a water pipeline. Hence, the authors considered two different types of flows of water inside a water pipeline and leakage locations on a water pipeline.

During the experiments, the flow of water (i.e., cyclic or continuous) was controlled manually by a solenoid valve fixed at the bottom of each water tank. For the laboratory experiments, the huge volumes of the sewer pipeline and water inside the pipeline would not allow the use of the sewer pipeline and water inside the pipeline for indoor laboratory experiments. Instead, a PVC pipeline and tap water were used throughout the experiments. The internal friction of the pipeline was neglected because of the smooth internal surface of the PVC pipeline and smaller distance between the leakage point and water inlet. The artificial leakage in the pipeline was created by making a hole, as shown in Figure $1 \mathrm{~b}$. Then, the pipeline was passed through the model box and buried in the soil.

For each case, the surface settlement or occurrence of a sinkhole was observed visually for around $30 \mathrm{~min}$. The complete experimental setup is shown in Figure 1, and all the cases considered in this study are shown in Figure 2. The objective of the experiments was to develop an understanding of the phenomena that occur when a sinkhole is created by the failure of an underground water pipeline. 


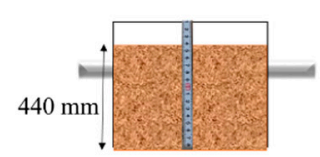

I (a)

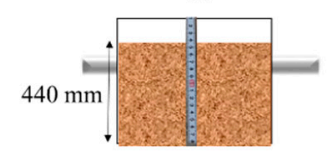

II (a)-(5 sec)

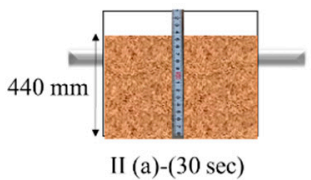

II (a)-(30 sec)

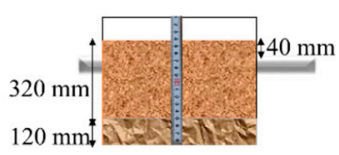

I (b)
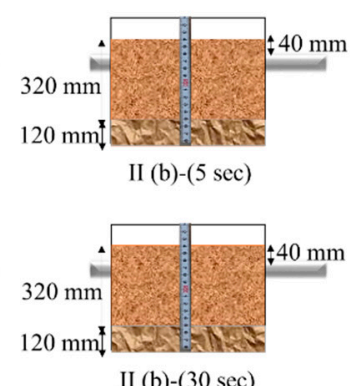

II (b)-(30 sec)

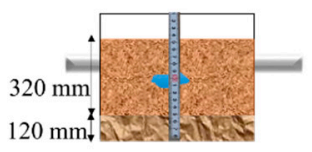

I (c)

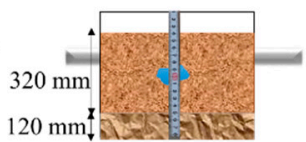

II (c)- $(5 \mathrm{sec})$

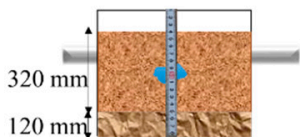

II (c)- $(30 \mathrm{sec})$

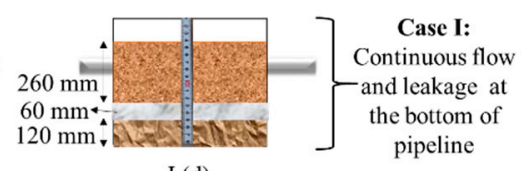

I (d)

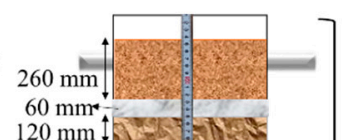

II (d)- $(5 \mathrm{sec})$

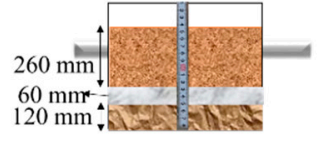

II (d)-(30 sec)
Case II: Non-

continuous flow and leakage at the bottom of

pipeline (two intervals of 05 and 30 seconds)

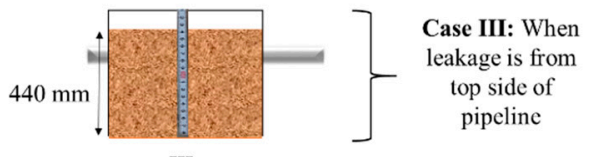

III

Figure 2. Illustration of the different cases considered in this study.

\subsection{Case I: Different Subsurface Soil Profiles with Continuous Flow and Leakage from the Bottom of the Pipeline}

In Case I, the leakage was at the bottom of the pipeline (i.e., in contact with water), and the water flow inside the pipeline was continuous. Hence, the water leaking from the pipeline was also continuous. Water flowed continuously through the pipeline for $30 \mathrm{~min}$ at a constant pressure, and the settlement was recorded each minute. The four soil profiles used are listed below:

Case I(a): SC

Case I(b): SC-BR

Case I(c): SC-C-BR

Case I(d): SC-LS-BR

For Case I(a), the pipeline leaking from the bottom passed through the SC soil profile. The maximum settlement was $26 \mathrm{~mm}$ at $30 \mathrm{~min}$. For Case I(b), the leaking pipeline passed through the model box with the SC-BR soil profile. The bedrock layer at the bottom of the model box was 120 $\mathrm{mm}$ thick, and the top layer of sandy clay was $450 \mathrm{~mm}$ thick, as shown in Figure 2. The maximum settlement was recorded at the center and was $57 \mathrm{~mm}$ at $30 \mathrm{~min}$. For both Cases I(a) and I(b), the soil in the model box just settled downward.

For Case I(c), the model box had two soil layers with the same thickness as Case I(b). However, it also included a cavity in the soil profile. The artificial cavity was created by placing $1600 \mathrm{~mm}^{3}$ of sugar cubes at the center of the model box immediately below the leakage position. The sugar cubes dissolved when they encountered water from the leak, which ultimately created a cavity. Afterward, the water flowed through the leaking pipeline for $30 \mathrm{~min}$. The maximum settlement was $135 \mathrm{~mm}$ at 30 min. In Case I(d), the soil strata had three layers: a bottom layer of bedrock $(120 \mathrm{~mm})$, a top layer of sandy clay $(260 \mathrm{~mm})$, and a middle layer of limestone $(60 \mathrm{~mm})$. The maximum settlement was $160 \mathrm{~mm}$ at the center of the model box. In Cases I(c) and I(d), after some time, the soil profile collapsed and created a sinkhole, as shown in Figure 3a.

The graphical representation Figure $3 b$ shows that in Cases I(a) and I(b), there was no collapse; the soil profile simply settled downward with time. In Cases I(c) and I(d), after some time, the soil profile rapidly collapsed to create a sinkhole. These collapses were due to the presence of a cavity and limestone in the soil profile. However, the collapse time and depth of the sinkhole differed for the two soil profiles. 
Final

\section{Settlement}

Case

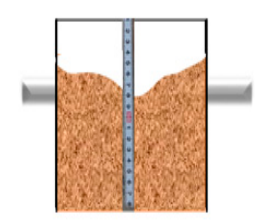

I(a)

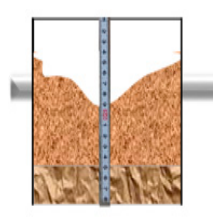

I(b)

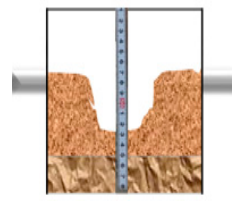

I(c)

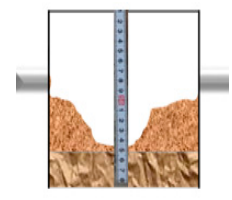

$\mathrm{I}(\mathrm{d})$

(a)

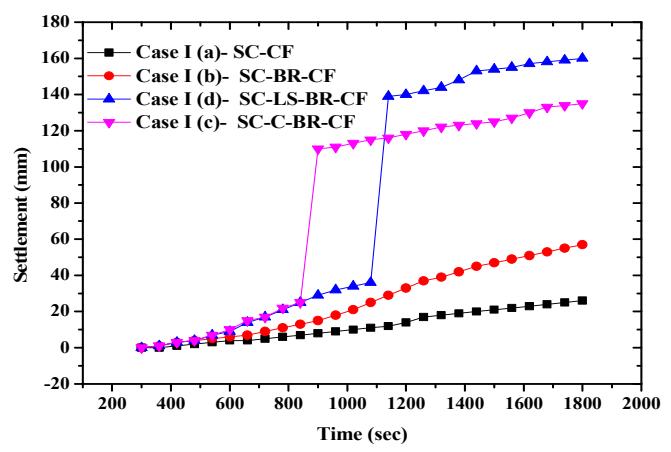

(b)

Figure 3. (a) Final settlement or collapse of each soil profile in case I. (b) Graphical representation of settlement vs. time for each case in Case I of continuous flow (CF).

\subsection{Case II: Leakage from the Bottom Side of a Sewer Pipeline with Cyclic Flow}

In real scenarios, the flow in a sewer pipeline is not always continuous. Thus, cyclic flow was considered in Case II with two different time intervals: 5 and $30 \mathrm{~s}$. The cyclic flow in the pipeline was achieved by manual control of the valve. For the first cyclic flow, the valve was opened and then closed every $5 \mathrm{~s}$. For the second cyclic flow, the valve was opened and then closed every $30 \mathrm{~s}$. The results are shown in Figure 4. For Case II(a), the two cyclic flows were tested with the SC soil profile to observe the settlement rate. For the 5-s cycle, the maximum settlement was $32 \mathrm{~mm}$; for the 30-s cycle, the maximum settlement was $30 \mathrm{~mm}$. Case II(b) used the SC-BR soil profile; this time, the maximum settlements for the 5-s and 30-s cyclic flow were 66 and $62 \mathrm{~mm}$, respectively. No collapse was noted for either the SC or SC-BR soil profile with the two cyclic flows. Case II(c) used the SC-C-BR soil profile and had maximum settlements of 156 and $150 \mathrm{~mm}$ for $5 \mathrm{~s}$ and $30 \mathrm{~s}$, and Case II(d) used the SC-LS-BR soil profile and had maximum settlements of 183 and $175 \mathrm{~mm}$ for the two cycles, respectively. In Cases II(c) and II(d), both soil profiles collapsed after some time, as shown in Figure 5. 


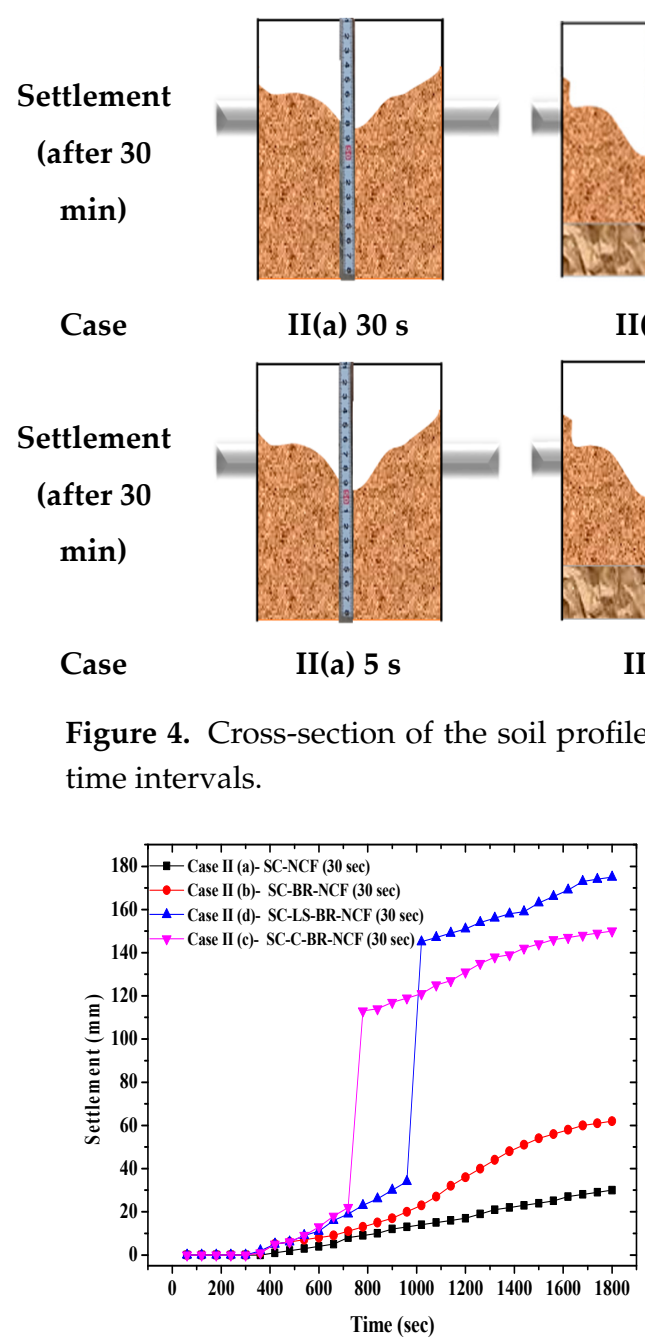

(a)

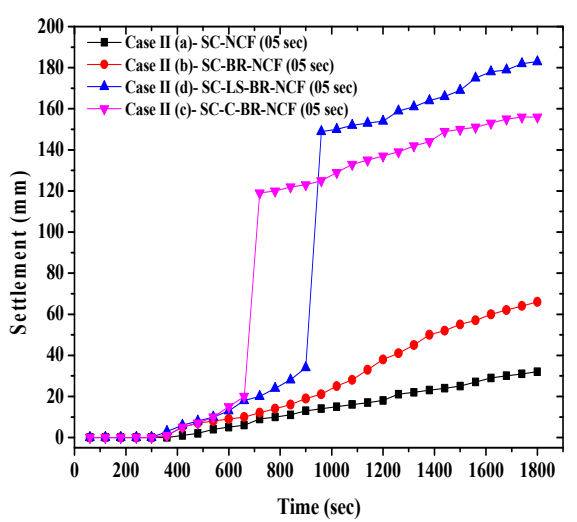

(b)

Figure 5. Settlement with respect to time for four different soil models and two different cyclic flows (non-continuous flow "NCF") in the pipeline (a) cyclic flow of $30 \mathrm{~s}$ and (b) cyclic flow of $5 \mathrm{~s}$.

To further confirm the significance of the results, a paired t-test was carried out on the continuous and cyclic settlement data. The statistical significance of the soil settlement data for the cyclic flow was evaluated with respect to the data for the continuous flow. The outcomes are listed in Table 4 and show that the data were statistically significant with $p$-value less than 0.05 ( $95 \%$ significance) in each case.

Table 4. Paired t-test results for statistical significance of the soil settlement data for the cyclic flow concerning the continuous flow.

\begin{tabular}{cccccc}
\hline \multirow{2}{*}{ Cases } & \multirow{2}{*}{ Alternative } & \multicolumn{4}{c}{ Continuous Flow } \\
\cline { 3 - 6 } & & SC & SC-BR & SC-C-BR & SC-LS-BR \\
\hline \multirow{4}{*}{ Cyclic flow (5 s cycle) } & SC & $1 \times 10^{-8}$ & - & - & - \\
& SC-BR & - & $2.1 \times 10^{-8}$ & - & - \\
& SC-C-BR & - & - & 0.00149 & 0.00013 \\
\hline & SC-LS-BR & - & - & - & - \\
\multirow{3}{*}{ Cyclic flow (30 s cycle) } & SC & $4.7 \times 10^{-8}$ & - & - & - \\
& SC-BR & - & $8.8 \times 10^{-8}$ & - & - \\
& SC-C-BR & - & - & 0.00839 & 0.00073 \\
\hline
\end{tabular}




\subsection{Case III: Leakage from the Top of the Sewer Pipeline}

In Case III, the soil above the PVC pipeline was sandy clay, as shown in Figure 2. Only the soil above the pipeline influenced sinkhole occurrence or settlement because it sank through the hole in the pipeline.

Hence, only the SC-BR soil profile was considered to assess the impact of leakage from the top. Figure 6 shows the stepwise effects when leakage was from the top of the pipeline. When water started to flow in the pipeline, initially there was no soil penetration (Figure 6a). With time the soil above started to penetrate the pipeline over time through the hole (Figure 6b), which generated a cavity.

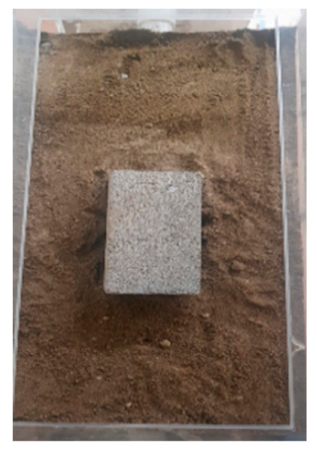

(a)

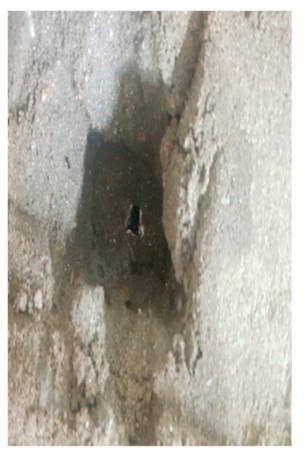

(d)

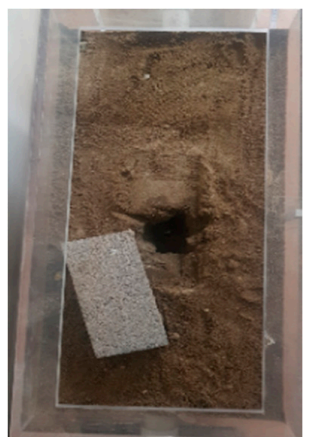

(b)

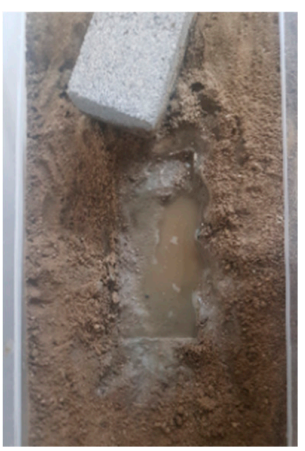

(e)

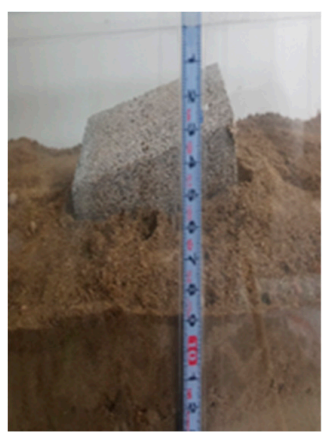

(c)

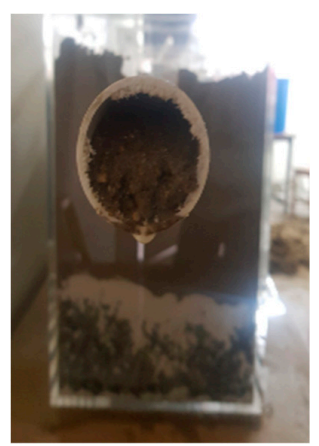

(f)

Figure 6. Systematic view of the sinkhole occurrence and ground collapse with leakage from the top of the pipeline.

Over time, the size of the cavity increased, and the load (brick) above the leakage collapsed downward (Figure 6c). The condition of the soil collapse is shown in Figure 6d after removing the load (brick). Then, the pipeline became blocked by the continuous intrusion of soil (Figure $6 \mathrm{f}$ ). After the pipeline was blocked, water started to come out from the leakage point where the sinkhole was created (Figure 6e).

\section{Results and Discussion}

The experimental results for Case I showed that a pipeline with continuous flow and leaking in the SC and SC-BR soil profiles only caused settlement over time. However, if the soil strata had a cavity or had limestone or carbonate rock present, then the ground would rapidly collapse at a certain point, and a sinkhole would occur.

For Case II, the settlement results with the two cyclic flows over time are presented in Figure 7a-d for each soil profile of SC, SC-BR, SC-C-BR, and SC-LS-BR, respectively. It can be noticed that in each case, the 5-s cyclic flow caused more settlement than the 30-s cyclic flow for each soil profile as illustrated in Figure 7a-d. The cyclic flows also caused more settlement than the continuous flow for each soil profile. 


\subsection{Experimental Results}

These results show that parameters such as the soil profile and position of the leakage significantly influence the speed of the occurrence of a sinkhole or ground subsidence. Hence, the data showed that cyclic flow in a pipeline is significant for any soil strata. However, the influence of the cyclic flow on sinkhole occurrence is meager compared to the influence of the subsurface soil strata, as illustrated in the combined graph of all cases in Figure 7e. To clearly demonstrate the relationship between the settlements for all considered soil profiles and water flows, the results for all cases shown in Figure 7a-d are combined in Figure 7e. Similarly, for Case III, when the pipeline was leaking from the top, the settlement in the soil profile was noted to be quicker compared to other cases when the pipeline was leaking form the bottom. However, the volume of settlement in Case III was less compared to the previous cases two cases (Cases I and II) when the pipeline was leaking from the bottom.

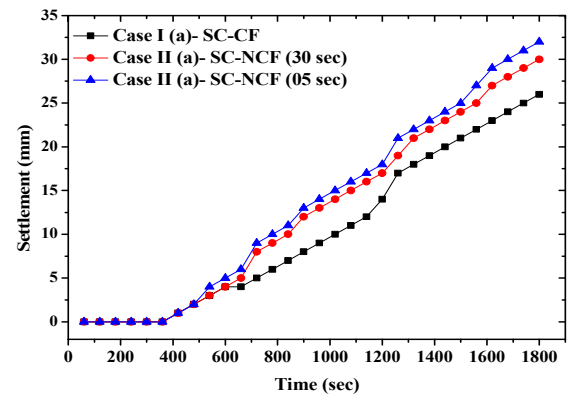

(a)

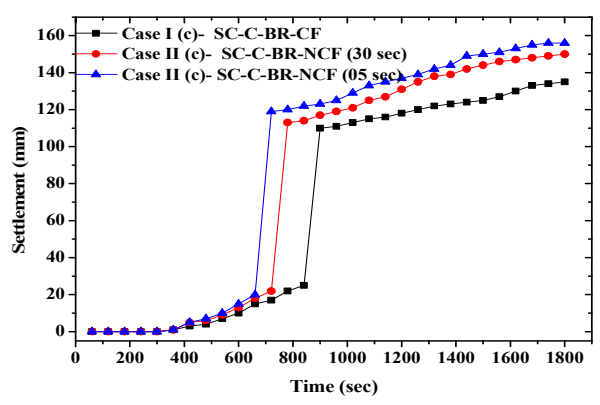

(c)

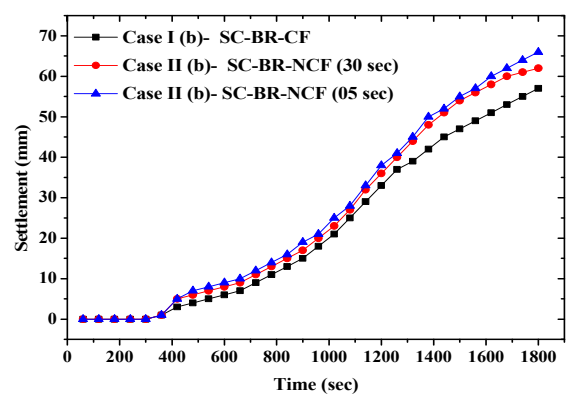

(b)

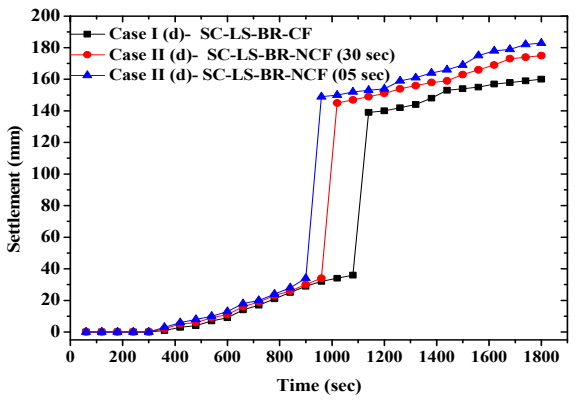

(d)

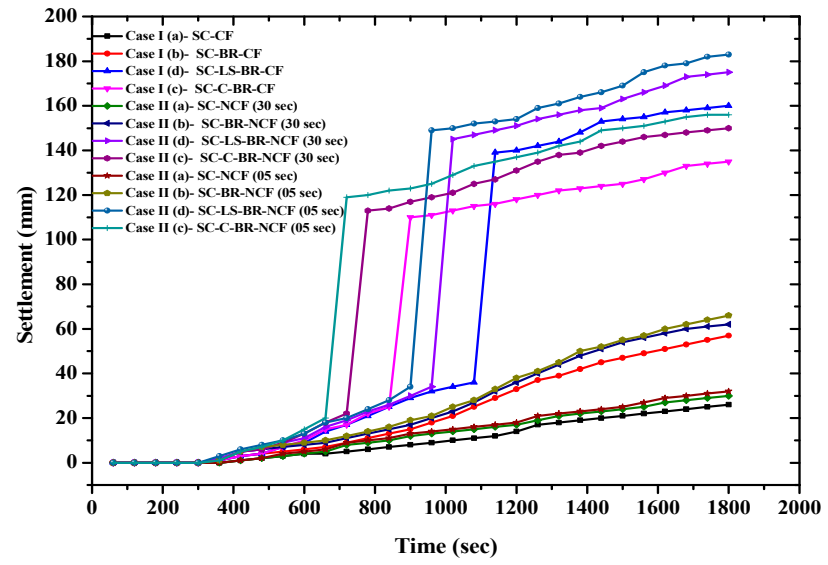

(e)

Figure 7. Graphical representation of settlement in different soil strata for the cases of (a) sandy clay (SC), (b) sandy clay-bedrock (SC-BR), (c) sandy clay-cavity-bedrock (SC-C-BR), and (d) sandy clay-limestone-bedrock (SC-LS-BR). (e) Combined illustration of all cases. 


\subsection{Regression Analysis}

Three factors were found to influence the settlement for any soil profile with respect to the time: the type of soil strata, type of water flow, and time interval in a cyclic flow. All the mentioned factors are related to the occurrence of a sinkhole and ground settlement due to leakage from underground water or sewer pipelines. The influence of all the considered factors on the settlement in any underground soil profile is analyzed by regression analysis using the $\mathrm{R}$ language. A regression model is developed to understand the significance of each factor on the settlement. The variables, type of soil profile (SP), type of flow in the pipeline (FT), the time interval of cyclic flow (TI), and time (t) were considered as independent variables. Settlement (output) is the dependent variable in the model. Each regression coefficient represents the change in settlement relative to a one-unit change in the respective independent variable. Hence from Table 5, it can be noticed that the variable SP has a highest coefficient value of 25.5 , and remaining coefficients have values of $16.1,0.075$, and -0.81 , respectively. Hence, the soil strata have a more significant influence than the other factors on sinkhole occurrence. The variables can be listed in order of significance as SP, FT, TI, and $\mathrm{t}(25.5,16.1,0.075$, and -0.81) respectively, as shown in Table 5. The negative value $(-0.81)$ of the coefficient with the variable TI is showing that the time interval in a cyclic flow has an inverse relation with the settlement in any subsurface soil strata after the leakage in an underground sewer or water pipeline. The graphical representation in Figure 7e also supports the inverse relation shown by regression analysis. As it can be noticed in the Figure 7e, the settlement for the 5-s time interval is higher compared to the time interval of $30 \mathrm{~s}$. Hence, with the increase in the time interval of a cyclic flow, the settlement rate decreases. Equation (1) elaborates the results of regression analysis and allows us to estimate the association between the dependent variable (settlement) and all the independent variables.

$$
\text { Settlement }(\mathrm{mm})=-107.6+25.5 \mathrm{SP}+16.1 \mathrm{FT}-0.81 \mathrm{TI}+0.075 \mathrm{t}
$$

whereas, $\mathrm{SP}=$ soil profile, $\mathrm{FT}=$ flow type, $\mathrm{TI}=$ time interval for cyclic flow (seconds), and $\mathrm{t}=$ time (seconds)

Table 5. Regression model showing the estimated values of coefficients and level of significance of each coefficient.

\begin{tabular}{cccccc}
\hline Coefficient & Estimate & Standard Error & T Value & $p$ Value & $\begin{array}{c}\text { Level of } \\
\text { Significance }\end{array}$ \\
\hline Intercept & -107.7 & 9.676 & -11.127 & $2 \times 10^{-16}$ & $* * *$ \\
Time Interval (TI) & -0.8113 & 0.3727 & -2.117 & 0.03016 & $*$ \\
Type of Flow (FT) & 16.14 & 5.990 & 2.694 & 0.00739 & $* *$ \\
Type of Soil Profile & 25.57 & 1.571 & 16.274 & $2 \times 10^{-16}$ & $* * *$ \\
(SP) & 0.07525 & 0.00383 & 22.242 & $2 \times 10^{-16}$ & $* * *$ \\
Time (t) & $* * *$ Very high, ${ }^{* *}$ High, ${ }^{*}$ Low.
\end{tabular}

The R-square values of the regression analysis are 0.6838 (multiple R-square) and 0.6802 (adjusted $\mathrm{R}$-square). R-square represents the proportion of variance, in the outcome variable settlement, that may be predicted by knowing the value of all the independent variables [26]. An R-square value close to 1 indicates that the model explains a large portion of the variance in the outcome variable. In this study, considering all 12 cases with all predictor variables, the R-square is equal to 0.6839 , meaning that $68.39 \%$ of the variance in the settlement can be predicted by considering all variables at the same time. Adding more variables can increase the R-square value, since the R-square variable represents the proportion of variance in the outcome variable [26]. However, in this study, each variable considered has a more or less significant effect on the output variable. Assessing the $p$-values in the regression model suggests that all the independent variables considered in this study are statistically significant. Hence, this model can be used as a significant regression model even with a small R-square value of 0.6838 . 
The area of settlement or collapse was also noted to vary for each case under different conditions, as given in Table 6 . The histogram in Figure 8 also clearly shows that the SC-LS-BR soil profile had the largest area of collapse under the various conditions.

Table 6. Area of collapse or subsidence in each case for the same period of time $\left(\mathrm{mm}^{2}\right)$.

\begin{tabular}{cccc}
\hline Soil Type & Continuous Flow & Cyclic Flow (30 s) & Cyclic Flow (5 s) \\
\hline SC & 10,480 & 13,155 & 13,750 \\
SC-BR & 14,630 & 18,580 & 19,699 \\
SC-C-BR & 34,640 & 41,952 & 44,329 \\
SC-LS-BR & 59,230 & 68,791 & 71,233 \\
\hline
\end{tabular}

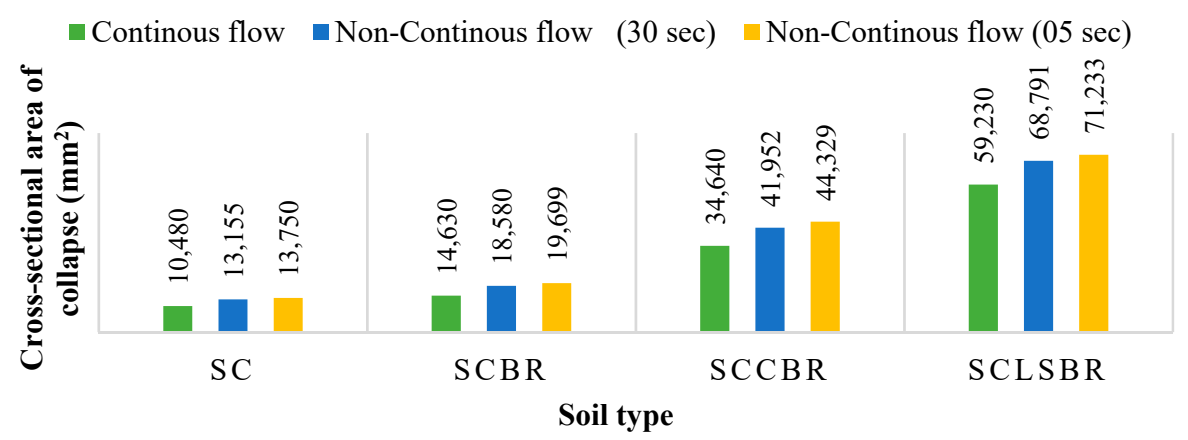

Figure 8. Area of collapse for different soils with a leaking pipeline $\left(\mathrm{mm}^{2}\right)$.

The results of the study were compiled into the manmade sinkhole risk prediction table (HM-SRPT), which is given in Table 7. The HM-SRPT indicates that a sinkhole will occur for the first five scenarios, while the soil profile will only settle downward for the next four scenarios without any collapse or occurrence of a sinkhole, as presented in Table 7. The criteria followed for the arrangement of the risk intensity in different soil profiles are leakage in water pipeline is based on the depth of settlement. As shown in the Table 7 under the column "Maximum settlement (mm)", $183 \mathrm{~mm}$ is the maximum settlement in the soil profile SC-LS-BR at $30 \mathrm{~min}, 160 \mathrm{~mm}, 156 \mathrm{~mm}, 135 \mathrm{~mm}$, and so on for other soil profiles and water flow conditions. Similarly, in the case of the pipeline leaking from the top, the risk intensity is kept very high ( $\mathrm{VH})$, because the soil profile was collapsed much earlier as compared to the other soil profiles when the pipeline was leaking from the bottom. Hence, the risk intensity is the highest for soil profiles when the leakage is from the top of the pipeline and for the SC-LS-BR soil profile when the pipeline leaks from the bottom.

Table 7. Predicted risk of sinkhole or ground settlement for different soil strata after leakage from an underground water/sewer pipeline.

\begin{tabular}{|c|c|c|c|c|c|c|c|c|c|c|}
\hline \multirow{2}{*}{$\begin{array}{l}\text { Leakage } \\
\text { Position }\end{array}$} & \multirow{2}{*}{ Flow Type } & \multirow{2}{*}{ Soil Strata } & \multirow{2}{*}{$\begin{array}{c}\text { Maximum } \\
\text { Settlement } \\
(\mathrm{mm})\end{array}$} & \multicolumn{5}{|c|}{ Risk Intensity } & \multicolumn{2}{|c|}{ Ground Effects } \\
\hline & & & & VL & $\mathbf{L}$ & $\mathbf{M}$ & $\mathbf{H}$ & VH & Settlement & Collapse \\
\hline Top & - & - & - & & & & & $\bullet$ & & $\bullet$ \\
\hline \multirow{8}{*}{ Bottom } & Cyclic & SC-LS-BR & 183 & & & & & $\bullet$ & & $\bullet$ \\
\hline & Continuous & SC-LS-BR & 160 & & & & $\bullet$ & & & $\bullet$ \\
\hline & Cyclic & SC-C-BR & 156 & & & & $\bullet$ & & & $\bullet$ \\
\hline & Continuous & SC-C-BR & 135 & & & $\bullet$ & & & & $\bullet$ \\
\hline & Cyclic & SC-BR & 66 & & • & & & & - & \\
\hline & Continuous & SC-BR & 57 & & $\bullet$ & & & & $\bullet$ & \\
\hline & Cyclic & SC & 32 & $\bullet$ & & & & & $\bullet$ & \\
\hline & Continuous & SC & 26 & $\bullet$ & & & & & - & \\
\hline
\end{tabular}

VL: Very low, L: Low, M: Moderate, H: High, VH: Very high, BR: Bedrock, C: Cavity, SC: Sandy clay, LS: Limestone/carbonate.

The results showed that the most important factor for sinkhole occurrence or settlement is the type of subsurface soil profile. A cyclic flow in a leaking pipeline was found to have a greater impact 
than a continuous flow. For cyclic flows, a shorter time interval has a greater impact than a longer time interval. The volume and depth of collapse or settlement were the greatest with the SC-LS-BR soil profile and smallest for the SC soil profile when the pipeline was leaking from the bottom. Among the cases considered, sinkhole occurrence was fastest when the pipeline leaked from the top.

Currently, ground penetrating radar [27], image processing and 3D visualization [28], trenching, and other methods are used to monitor sinkholes, ground collapse, and ground settlement. However, these practices are energy-intensive, time-consuming, and costly. In addition, these methods cannot monitor urban sinkholes in real time. Hence, urban areas first need to be divided into zones based on the risk level.

Risk prediction can help public and private maintenance authorities such as urban water management authorities and geological departments take action as soon as possible to prevent accidents due to leaking underground sewer and/or water pipelines. In such cases, the regression model developed in this study can be helpful for the public and private authorities to predict and decide the zones in urban areas that need urgent monitoring to overcome any settlement or collapse due to leakage in an underground pipeline. However, many experiments need to be performed to determine the characteristics and develop adequate guidelines. There is a notable lack of manmade sinkhole models that consider various factors for risk prediction. The experimental results for different subsurface profiles in this study can be used to determine the sinkhole risk in different areas and help divide an area into zones based on the subsurface soil profile. Manmade sinkholes in urban areas occur due to leakage in underground sewer and water pipelines, tunneling, deep foundations, mining, and underground water table. However, in this study, the authors only considered the manmade sinkholes due to leakage in underground sewer and water pipelines. In the future, the results can be used to develop an SRI by considering other various aspects of manmade sinkholes in urban areas such as tunneling, deep foundations, mining, and the underground water table.

\section{Conclusions}

This study assessed the effects of leaking underground sewer and water pipelines on different subsurface soil profiles under different conditions (i.e., type of water flow and leakage position). The type of subsurface soil profile, type of water flow, and leakage position were each found to play a role in sinkhole occurrence. The type of soil strata was determined to be the critical parameter for a sinkhole or ground settlement to occur. The experimental results indicated that the leakage of a sewer or water pipeline in a SC-C-BR soil profile has a high risk of sinkhole occurrence, especially when the pipeline is leaking from the top. Underground subway construction is an example of a subsurface soil profile with cavities or spaces that lead to settlement or collapse if a nearby sewer or water pipeline leaks [29]. A continuously leaking underground sewer or water pipeline has a smaller effect on sinkhole occurrence than a leaking pipeline with a cyclic flow considering the same duration of leaking time and same quantity of leaking water. These experimental results were further validated by analyzing the data by developing a regression model. The regression model also showed that the specific soil profile for each considered factor was significant for the end results in each considered case. On the basis of the results of experiments and the analysis of the regression model, the risk level of ground settlement or sinkhole occurrence was predicted and summarized in Table 7 . Future research on developing an SRI would help with addressing the issues of sinkhole and ground settlement. Although many sinkhole detection methods have been developed, predicting sinkholes is still a challenge. In addition, conventional methods are inappropriate for a large area because of their high cost. Therefore, high-risk areas need to be predicted first and prioritized to make such methods and techniques cost-effective.

Author Contributions: Conceptualization and design of study methodology are done by H.A. and J.-h.C. The whole study was supervised by J.-h.C. Data Analysis, Interpretation and data collection are done by H.A. The original draft is written by H.A. All authors have read and agreed to the published version of the manuscript. 
Funding: This work was supported and funded by the Basic Science Research Program through the National Research Foundation of Korea (NRF) and funded by the Ministry of Education (2016R1A6A1A03012812 and 2017R1D1A1B03036200).

Conflicts of Interest: The authors declare no conflict of interest.

\section{References}

1. Fang, Q.; Zhang, D.; Wong, L.N.Y. Environmental risk management for a cross interchange subway station construction in China. Tunn. Undergr. Space Technol. 2011, 26, 750-763. [CrossRef]

2. Hou, Y.; Fang, Q.; Zhang, D.; Wong, L.N.Y. Excavation failure due to pipeline damage during shallow tunnelling in soft ground. Tunn. Undergr. Space Technol. 2015, 46, 76-84. [CrossRef]

3. Kang, J.M.; Choi, C.H.; Kwak, P.J.; Kim, J.Y.; Park, S.H.; Park, Y.S. Ground Subsidence Monitoring and Risk Assessment around Water Supply and Sewerage. J. Korea. Soc. Civ. Eng. 2017, 65, $22-27$.

4. Brinkmann, R.; Parise, M.; Dye, D. Sinkhole distribution in a rapidly developing urban environment: Hillsborough County, Tampa Bay area, Florida. Eng. Geol. 2008, 99, 169-184. [CrossRef]

5. Kuniansky, E.L.; Weary, D.J.; Kaufmann, J.E. The current status of mapping karst areas and availability of public sinkhole-risk resources in karst terrains of the United States. Hydrogeol. J. 2016, 24, 613-624. [CrossRef]

6. Lee, E.J.; Shin, S.Y.; Ko, B.C.; Chang, C. Early sinkhole detection using a drone-based thermal camera and image processing. Infrared Phys. Technol. 2016, 78, 223-232. [CrossRef]

7. Jaya, P. Two Pedestrians Fall Into 3m-Deep Sinkhole in Seoul. Star Online. 25 February 2015. Available online: https://www.thestar.com.my/news/world/2015/02/25/sink-hole-seoul/\#wGy2vrEth6cJBmhd.99 (accessed on 1 November 2019).

8. Julian, R. Japan Giant Sinkhole in Fukuoka Repaired in a Week Begins to Sink Again. Daily Mail Online. 28 November 2016. Available online: https:/www.dailymail.co.uk/news/article-3978468/Panic-Japangiantsinkhole-repaired-just-week-begins-sink-forcing-road-close-did-carry-repairs-quickly.html (accessed on 1 November 2019).

9. Steve, R.; Haworth, J. Police Officer Killed After Massive Sinkhole Opens Up in Road Swallowing Two Cars. Mirror. 6 December 2016. Available online: https://www.mirror.co.uk/news/world-news/man-killedafterbeing-swallowed-9397110 (accessed on 2 November 2019).

10. Roger, S. Huge Sinkholes Are Now Appearing in The Wrong Places. AP News. 9 May 2017. Available online: https://apnews.com/41a17da407d241769e54085a8118ac7c (accessed on 1 November 2019).

11. Rosdi, M.A.H.M.; Othman, A.N.; Zubir, M.A.M.; Latif, Z.A.; Yusoff, Z.M. Sinkhole susceptibility hazard zones using GIS and Analytical Hierarchical Process (AHP): A case study of Kuala Lumpur and Ampang Jaya. ISPRS Int. Arch. Photogramm. Remote Sens. Spat. Inf. Sci. 2017, XLII-4/W5, 145-151. [CrossRef]

12. Kwak, P.J.; Park, S.H.; Choi, C.H.; Lee, H.D.; Kang, J.M.; Lee, I.H. IoT (Internet of Things)-based underground risk assessment system surrounding water pipes in Korea. Int. J. Control Autom. 2015, 8, 183-190. [CrossRef]

13. McNamara, A.; Kearsley, E.P. Using pipe deflection to detect sinkhole development. In Proceedings of the 9th International Conference on Physical Modelling in Geotechnics (ICPMG 2018), London, UK, 17-20 July 2018; pp. 1081-1086.

14. Ihm, M.H. Ground Subsidence Risk Ratings for Practitioners to predict Ground Collapse during Excavation (GSRp). Int. J. Adv. Cult. Technol. 2018, 6, 255-261.

15. Sartain, N.; Mian, J.; Ooriordan, N.; Storry, R. Case Study On The Assessment of Sinkhole Risk for the Development of Infrastructure Over Karstic Ground. In Proceedings of the 3rd Intenational Symposium on Geotechnical Safety and Risk ISGSR 2011, Karlsruhe, Germany, 6-8 April 2011; pp. 635-642.

16. Buttrick, D.; Van Schalkwyk, A. Hazard and risk assessment of sinkhole formation on dolomite land in South Africa. Environ. Geol. 1998, 36, 170-178. [CrossRef]

17. Augarde, C.E.; Lyamin, A.V.; Sloan, S.W. Prediction of Undrained Sinkhole Collapse. J. Geotech. Geoenviron. Eng. 2003, 129, 197-205. [CrossRef]

18. Ali, H.; Choi, J. A Review of Underground Pipeline Leakage and Sinkhole Monitoring Methods Based on Wireless Sensor Networking. Sustainability 2019, 11, 4007. [CrossRef] 
19. Tao, X.; Ye, M.; Wang, X.; Wang, D.; Castro, R.P.; Zhao, J. Experimental and Numerical Investigation of Sinkhole Development and Collapse in Central Florida. In Proceedings of the 14th Multidisciplinary Conference on Sinkholes and the Engineering and Environmental Impacts of Karst, University of South Florida Tampa Library, Tampa, FL, USA; 2015; pp. 501-506.

20. Rawal, K.; Wang, Z.M.; Hu, L.B. Exploring the Geomechanics of Sinkholes: A Numerical Simulation Approach. In Proceedings of the Geotechnical Special Publication, American Society of Civil Engineers (ASCE), Chicago, IL, USA, 14-18 August 2016; pp. 372-381.

21. Oz, I.; Eyal, S.; Yoseph, Y.; Ittai, G.; Elad, L.; Haim, G. Salt dissolution and sinkhole formation: Results of laboratory experiments. J. Geophys. Res. Earth Surf. 2016, 121, 1746-1762. [CrossRef]

22. Al-Halbouni, D.; Holohan, E.; Taheri, A.; Schoper, M.P.J. Geomechanical modelling of sinkhole development using Distinct Elements: Model verification for a single void space and application to the Dead Sea area. Solid Earth 2018, 9, 1341-1373. [CrossRef]

23. Soliman, M.; Perez, A.; Nam, B.H.; Ye, M. Physical and Numerical Analysis on the Mechanical Behavior of Cover-collapse Sinkholes in Central Florida. In Proceedings of the 15th Multidisciplinary Conference on Sinkholes and the Engineering and Environmental Impacts of Karst and the 3rd Appalachian Karst Symposium, Shepherdstown, WV, USA, 2-6 April 2018; National Cave and Karst Research Institute: Florida, FL, USA, 2018.

24. Sas, W.; Głuchowski, A.; Gabrys, K.; Szymański, A. Application of cyclic CBR test for the estimation of resilient modulus in the pavement construction. In Proceedings of the XVI ECSMGE Geotechnical Engineering for Infrastructure and Development, Edinburgh, UK, 13-17 September 2015; pp. 3747-3752.

25. Karoui, T.; Jeong, S.Y.; Jeong, Y.H.; Kim, D.S. Experimental study of ground subsidence mechanism caused by sewer pipe cracks. Appl. Sci. 2018, 8, 679. [CrossRef]

26. James, G.; Witten, D.; Hastie, T.; Tibshirani, R. Statistical Learning. In An Introduction to Statistical Learning; Springer: New York, NY, USA, 2013; pp. 15-57.

27. Zhang, F.; Xie, X.; Huang, H. Application of ground penetrating radar in grouting evaluation for shield tunnel construction. Tunn. Undergr. Space Technol. 2010, 25, 99-107. [CrossRef]

28. Providakis, S.; Rogers, C.D.F.; Chapman, D.N. Predictions of settlement risk induced by tunnelling using BIM and 3D visualization tools. Tunn. Undergr. Space Technol. 2019, 92, 103049. [CrossRef]

29. Gao, C.; Zhou, Z.; Yang, W.; Lin, C.; Li, L.; Wang, J. Model test and numerical simulation research of water leakage in operating tunnels passing through intersecting faults. Tunn. Undergr. Space Technol. 2019, 94, 103134. [CrossRef]

(C) 2019 by the authors. Licensee MDPI, Basel, Switzerland. This article is an open access article distributed under the terms and conditions of the Creative Commons Attribution (CC BY) license (http://creativecommons.org/licenses/by/4.0/). 